\title{
The efficacy of the different endoscopic treatments versus sham, pharmacologic or surgical methods for chronic gastroesophageal reflux disease: a systematic review and meta-analysis
}

\author{
Martin Andrés CORONEL, Wanderley Marques BERNARDO, Diogo Turiani Hourneaux de MOURA, \\ Eduardo Turiani Hourneaux de MOURA, Igor Braga RIBEIRO and Eduardo Guimarães Hourneaux de MOURA
}

Received 12/3/2018

Accepted 14/5/2018

\begin{abstract}
Background - Endoscopic antireflux treatments for gastroesophageal reflux disease (GERD) are still evolving, and most of the published studies address symptom relief in the short-term. Objective - We aimed to perform a systematic review and meta-analysis focused on evaluating the efficacy of the different endoscopic procedures. Methods - Search was restricted to randomized controlled trials (RCTs) on MedLine, Cochrane, SciELO, and EMBASE for patients with chronic GERD ( $>6$ months), over 18 years old and available follow up of at least 3 months. The main outcome was to evaluate the efficacy of the different endoscopic treatments compared to sham, pharmacological or surgical treatment. Efficacy was measured by different subjective and objective outcomes. Results - We analyzed data from 16 RCT, totaling 1085 patients. The efficacy of endoscopic treatments compared to sham and proton pump inhibitors (PPIs) treatment showed a significant difference up to 6 months in favor of endoscopy with no heterogeneity $(P<0.00001)\left(\mathrm{I}^{2}: 0 \%\right)$. The subgroup analysis showed a statistically significant difference up to 6 months in favor of endoscopy: endoscopy vs PPI $(P<0.00001)\left(\mathrm{I}^{2}: 39 \%\right)$. Endoscopy vs sham $(P<0.00001)\left(\mathrm{I}^{2}: 0 \%\right)$. Most subjective and objective outcomes were statistically significant in favor of endoscopy up to 6 and 12 months follow up. Conclusion - This systematic review and meta-analysis shows a good short-term efficacy in favor of endoscopic procedures when comparing them to a sham and pharmacological or surgical treatment. Data on long-term follow up is lacking and this should be explored in future studies.
\end{abstract}

HEADINGS - Gastroesophageal reflux, therapy. Gastrointestinal endoscopy. Follow-Up Studies. Review.

\section{INTRODUCTION}

Gastroesophageal reflux disease (GERD) is a disease defined as a chronic condition resulting from the reflux of gastroduodenal contents into the esophagus and adjacent organs. It is characterized by symptoms of retrosternal burning (heartburn) and acid regurgitation. Occurring in $6.3 \%$ of the US adult population at a frequency of at least twice a week ${ }^{(1,2)}$ There has been an increasing prevalence of GERD $(10 \%-20 \%)$ in adults in Western populations in recent decades. It is estimated that up to $28 \%$ of adults have weekly symptoms of retrosternal burning and acid regurgitation ${ }^{(3)}$. In Brazil, about $12 \%$ of the population is affected by the disease $\mathrm{e}^{(4)}$.

The symptoms of persistent mild reflux affect the physical, psychological well-being and quality of life of patients. Uncontrolled GERD can result in complications, including erosive esophagitis, with consequent peptic stenosis, and extraesophageal manifestations that require additional therapy. GERD also increases the risk of developing Barrett's esophagus and subsequent esophageal adenocarcinoma. Recent reports demonstrate a worldwide increase in the annual incidence of esophageal cancer in parallel with the increasing prevalence of GERD ${ }^{(5,6)}$.
The use of proton pump inhibitors (PPIs) in conjunction with lifestyle modifications continues to be the primary therapy. However, the effectiveness of this intervention is often hampered by adherence, costs and risks associated with the long-term use of PPIs. Anti-reflux surgery is an option for patients with refractory symptoms or in those in whom medical therapy is contraindicated or undesirable. Surgery is based on the reconstruction of the antireflux barrier, usually associated with the posterior closure of the diaphragmatic hiatus. These operations can be performed in an open fashion and more recently laparoscopically ${ }^{(7,8)}$.

Surgical treatment, although effective in the short term, may be associated with non-negligible morbidity and there is a growing concern about late recurrence ${ }^{(9)}$. Although conventional surgery has an acceptable safety profile, there has been increasing interest in alternative minimally invasive endoscopic treatments that may offer similar results with an increased safety profile and faster recovery times.

Endoscopic therapies have emerged as a possible treatment options for individuals with GERD, particularly when refractory to the use of PPIs. These techniques can be categorized into three groups: 1) Endoluminal suture or plication of the gastro esophageal 
junction $(\mathrm{GEJ})\left(\right.$ EndoCinch $^{\circledR}, \mathrm{NDO}$ Surgical ${ }^{\circledR}, \mathrm{MUSE}^{\circledR}$ Esophyx $\left.^{\circledR}\right)$; 2) Radiofrequency (RF) thermal therapy of the lower esophageal sphincter (LES) $\left(\right.$ Stretta $\left.^{\circledR}\right)$; and 3) Injection or implantation of biopolymers in GEJ (Enteryx ${ }^{\circledR}$, Gatekeeper ${ }^{\circledR}$, among others) ${ }^{(10)}$. Due to the continuous evolution of these therapies, multiple prospective, randomized clinical trials evaluating the benefits of these interventions have been performed.

Two meta-analysis recently described on the literature, one showing an overall increased benefit of transoral incisionless fundoplication (TIF) performed with the Esophy $\mathrm{X}^{\circledR}$ device when compared to patients who did not undergo $\operatorname{TIF}^{(11)}$. The second study analyzing the Stretta ${ }^{\circledR}$ procedure, showed that there were no significant changes in physiologic parameters (time spent at a $\mathrm{pH}$ less than 4 and lower esophageal sphincter pressure (LESP), ability to stop PPIs, or health related quality of life score (HRQL) when compared with sham therapy ${ }^{(12)}$. The aim of our study is to perform a systematic review and meta-analysis on the efficacy of all randomized controlled trials evaluating the efficacy of all available endoscopic treatments when compared to a sham procedure or therapy with pharmacologic agents like PPIs or laparoscopic anti reflux surgery (LARS).

\section{METHODS}

\section{Protocol and registration}

The present systematic review and meta-analysis is performed according with the PRISMA statement ${ }^{(13)}$. This study was registered at www.crd.york.ac.uk/PROSPERO. Registration number is: CRD42017064534. This study was exempt from ethical approval because analysis involved only de-identify data.

\section{Search strategy}

We searched in MedLine (Pubmed), EMBASE, Cochrane Central and SciELO (1980 to March 22, 2018), for the studies assessing the efficacy of all endoscopic treatment for GERD.

\section{Terms used to search Medline}

"Gastric Acid Reflux," or 'Esophageal Acid reflux "Gastroesophageal Reflux Disease," or "GERD” AND "Endoscopic treatment," or "Gastrointestinal Endoscopy," or "Surgical Procedures," or "Gastrointestinal Surgeries".

\section{Terms used to search in EMBASE, Cochrane Central, SciELO}

(Gastroesophageal reflux disease) AND ("Endoscopic treatment" or "Gastrointestinal Surgical treatment").

The search was restricted to human studies with no language or date of publication restriction in peer- reviewed journals. Two authors (M.C. and B.W.) independently screened each of the potential titles, abstracts in the primary search to exclude studies that did not address the research question of interest, based on pre-specified inclusion and exclusion criteria (detailed below). The full text of the remaining articles was examined to determine whether it contained relevant information. Areas of disagreement or uncertainty in article selection were resolved by consensus, and in discussion with a coauthor (D.T.M). Conference proceedings, which did not undergo peer review, were excluded from our analysis. We attempted to contact the corresponding authors to provide additional information on trials if required.

\section{Study selection}

Selection of prospective, randomized clinical trials evaluating the efficacy of the different endoscopic treatments versus any other interventions (sham, PPI, surgery) for chronic GERD was performed. Studies that met the following criteria were included: patients over 18 years of age, undergoing endoscopic procedures for chronic GERD (defined as symptoms equal or over 6 months in duration), more than 3 months follow up period. Types of intervention and controls: Available endoscopic therapies: transoral incisionless fundoplication (TIF2) by the Esophy $\mathrm{X}^{\circledR}$ device, surgical plication by NDO surgical ${ }^{\circledR}$ device, radiofrequency therapy by the Stretta ${ }^{\circledR}$ device; endoscopic suturing system by EndoCinch ${ }^{\circledR}$ device, injectable esophageal prostheses by Gatekeeper ${ }^{\circledR}$ device, biocompatible non-resorbable copolymer by the Enteryx ${ }^{\circledR}$ device. Controls were performed via a sham procedure, pharmacological treatments (PPIs) or surgery (LARS). Exclusion criteria: retrospective, prospective non-randomized, studies without full text, studies that were requested to the authors without being answered and studies that compare two endoscopic procedures head to head.

\section{Data extraction and quality assessment}

Data on study characteristic, such as, author name, reference, year of publication; sample size and population, type of endoscopic intervention, type of control group (sham, PPI or LARS), subjective or objective outcomes, follow-up period and type of analysis (per protocol or intention to treat) were abstracted onto a standardized data form by at least two authors independently (M.C, B.W, D.T.M). Details of data abstraction are reported in FIGURE 1. The quality of each study was classified according to the risk for bias, considering: the question to be investigated, a correct randomization protocol, an adequate subject allocation,

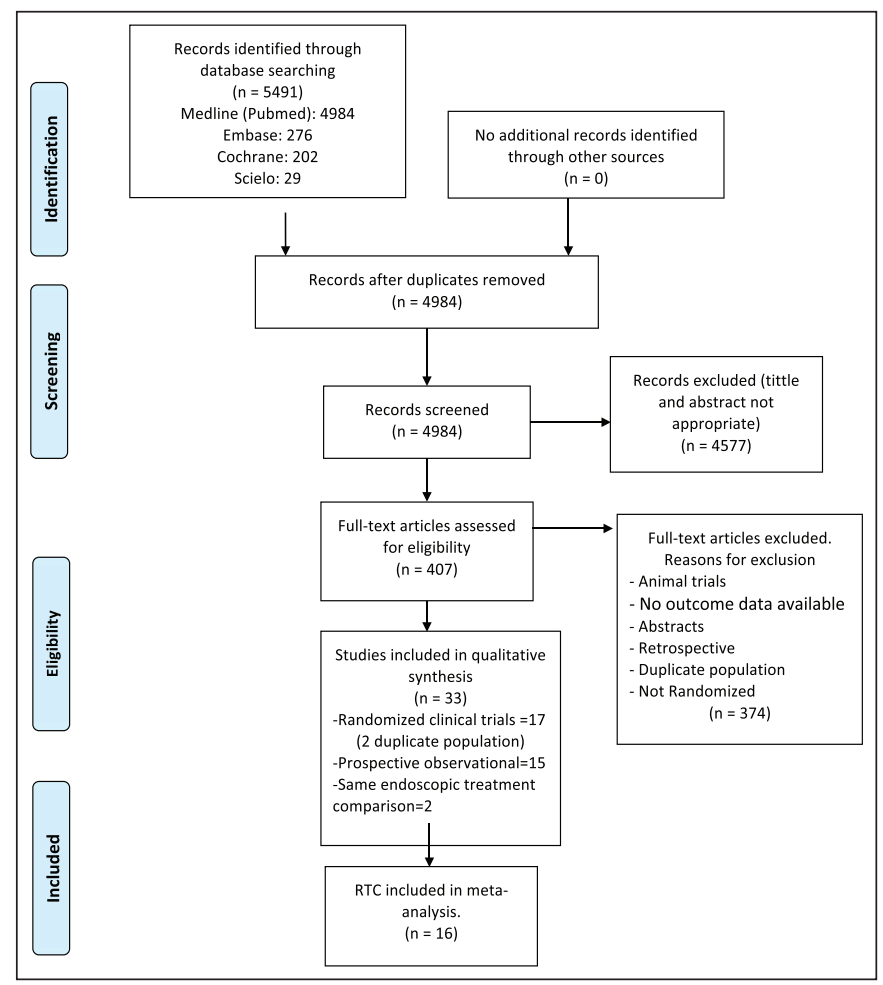

FIGURE 1. Flow diagram of the data extraction methodology. 
importance of the blinding, patient losses in each study, each prognostic factor, outcome reporting and analysis by intention to treat or by protocol. In addition, the JADAD scale or score was used to independently assess the methodological quality of each clinical trial ${ }^{(14)}$. (FIGURE 2.A and FIGURE 2.B).

\section{Outcomes assessed}

The main or primary outcome of the study is to measure the overall efficacy of endoscopic treatments versus other interventions (PPI or LARS) or sham procedure for the treatment of chronic GERD. Subgroup analysis was assessed individually

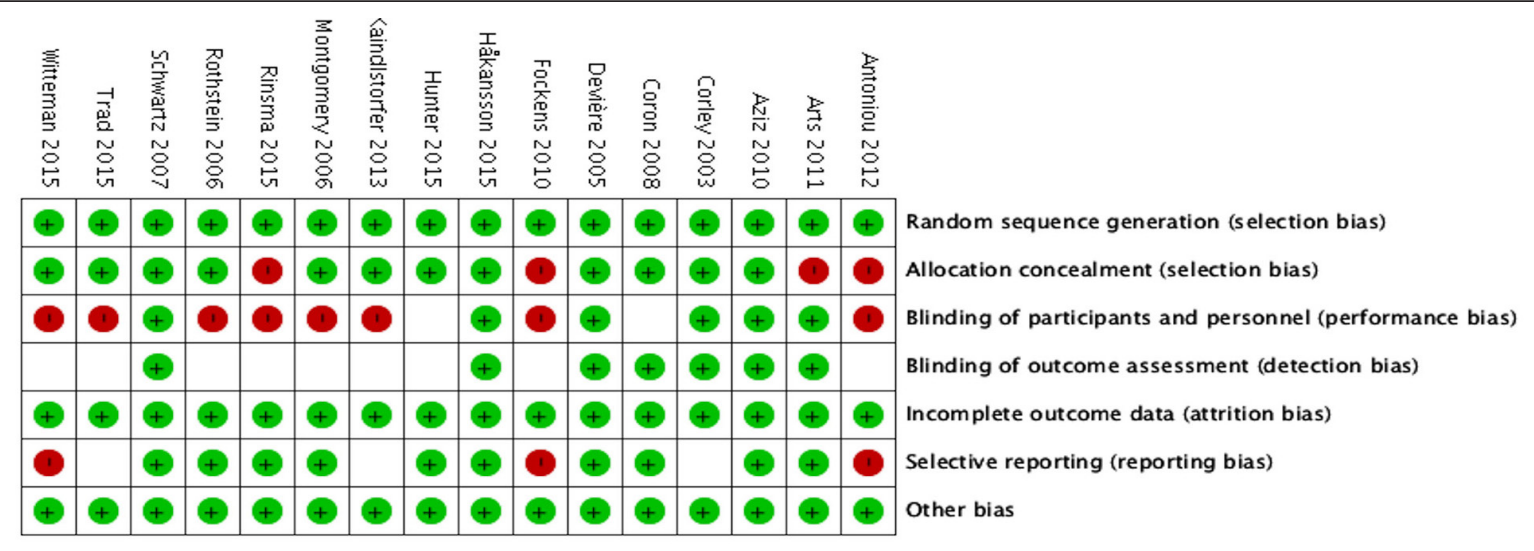

Random sequence generation (selection bias)

Allocation concealment (selection bias)

Blinding of participants and personnel (performance bias)

Blinding of outcome assessment (detection bias)

Incomplete outcome data (attrition bias)

Selective reporting (reporting bias)

Other bias

Low risk of bias

unclear risk of bias

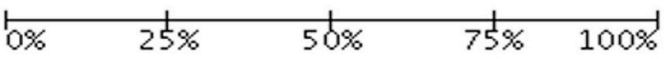

High risk of bias

FIGURE 2.A. Summary of risk of bias of included RCT's.

\begin{tabular}{|l|c|c|c|c|c|c|c|c|c|}
\hline Study & Question & Randomization & Allocation & Double Blinding & Losses & Prognosis & Outcomes & ITT & Jadad Scale \\
\hline Antoniou, 2012 & Yes & Yes & No & No & Yes & Yes & Yes & No & $\mathbf{3}$ \\
\hline Arts, 2011 & Yes & Yes & No & Yes & Yes & Yes & Yes & Yes & $\mathbf{3}$ \\
\hline Aziz, 2010 & Yes & Yes & Yes & Yes & Yes & Yes & Yes & Yes & $\mathbf{5}$ \\
\hline Corley, 2003 & Yes & Yes & Yes & Yes & Yes & Yes & Yes & No & $\mathbf{5}$ \\
\hline Coron, 2008 & Yes & Yes & Yes & Yes & Yes & Yes & Yes & Yes & $\mathbf{5}$ \\
\hline Devière, 2005 & Yes & Yes & Yes & Yes & Yes & Yes & Yes & Yes & 4 \\
\hline Fockens, 2010 & Yes & Yes & No & No & Yes & Yes & Yes & No & 3 \\
\hline Håkansson, 2015 & Yes & Yes & Yes & Yes & Yes & Yes & Yes & Yes & $\mathbf{5}$ \\
\hline Hunter, 2015 & Yes & Yes & Yes & No & Yes & Yes & Yes & Yes & $\mathbf{4}$ \\
\hline Kaindlstorfer, 2013 & Yes & Yes & Yes & No & No & Yes & Yes & No & $\mathbf{3}$ \\
\hline Montgomery, 2006 & Yes & Yes & Yes & No & Yes & Yes & Yes & Yes & $\mathbf{4}$ \\
\hline Risma, 2015 & Yes & Yes & No & No & Yes & Yes & Yes & Yes & $\mathbf{3}$ \\
\hline Rothstein, 2006 & Yes & Yes & Yes & No & Yes & Yes & Yes & Yes & $\mathbf{5}$ \\
\hline Schwartz, 2007 & Yes & Yes & Yes & Yes & Yes & Yes & Yes & Yes & $\mathbf{5}$ \\
\hline Trad, 2015 & Yes & Yes & Yes & No & Yes & Yes & Yes & No & $\mathbf{4}$ \\
\hline Witteman, 2015 & Yes & Yes & Yes & No & Yes & Yes & Yes & No & 4 \\
\hline
\end{tabular}

FIGURE 2.B. Summary of risk of bias of included RCT's. 
for 3, 6 and 12 months follow up for the different outcomes. The outcomes were categorized as objective: 1) normalization of esophageal acid $\mathrm{pH}$ (total proportion of time with a $\mathrm{pH}<4$ in 24-h period) $)^{(15)}$; 2) mean percent of total time of esophageal $\mathrm{pH}<4$ in 24-hours period ${ }^{(15)}$; 3) healing esophagitis; 4) worsening esophagitis; 5) mean number of reflux episodes; 6) lower esophageal sphincter resting pressure (LESRP); and subjective: 1) time in remission (more than 6 months without the use of PPI); 2) number of patients with GERD health related quality of life (HRQL) score $>50 \%$ improvement $\left.{ }^{(16,17)} ; 3\right)$ mean GERD HRQL score ${ }^{(16,17)}$; 4) elimination of troublesome regurgitation as defined as per the Montreal consensus $\left.{ }^{(16)} ; 5\right)$ heartburn score ${ }^{(18)}$; 6) DeMeester score ${ }^{(18)}$. All extracted data were placed according to the intention-to-treat analysis and protocol information.

For this meta-analysis, if there was treatment crossover to other interventions, no data analysis was performed.

\section{Statistical analysis}

This meta-analysis, follows the methodology as previously suggested by DerSimonian and Laird ${ }^{(19)}$. We used a fixed-effect model to determine the efficacy of all endoscopic treatments vs any other type of interventions. Heterogeneity was assessed using the $\mathrm{I}^{2}$ statistic to estimate what proportion of total variances across studies was due to heterogeneity or chance. As previously reported, $\mathrm{I}^{2}$ values of $25 \%, 50 \%$, and $75 \%$ represent low, moderate, and high levels of heterogeneity, respectively. Once heterogeneity was noted, to identify potential sources of heterogeneity, subgroup analysis was performed by excluding potential outliers. Visual inspection of publication bias was performed by using a funnel plot and calculated by the Egger test $^{(20)}$. The absolute risk difference with a $95 \%$ confidence intervals (CIs) were calculated for all point estimates, and a $P$ value $<0.05$ was considered statistically significant. The difference between the main outcome as well as the subgroup analysis was calculated using the risk difference with dichotomous variables and the mean difference with continuous variables. The Mantel Hantzel test for the analysis of categorical variables and inverse variance for continuous variables. The number need to treat (NNT) was also calculated. Statistical analysis was performed using the RevMan 5.3 software (Copenhagen, The Nordic Cochrane Center, The Cochrane Collaboration, 2014) and VassarStats software: Website for Statistical Computation (Richard Lowry 2001-2017 All rights reserved).

\section{RESULTS}

A total of 5491 citations were identified by using our search strategy (PubMed, SciELO, EMBASE, and Cochrane databases, provided 4984, 29, 276, and 202 articles respectively) we excluded 5,084 abstracts after initial screening, and assessed 407 full-text articles for eligibility. Of these, 391 studies did not meet inclusion criteria (animal trials, no outcome data available, abstracts, retrospective, duplicate population not randomized, comparison between two endoscopic procedures, comparison of a different technique of the same endoscopic treatment and not relevant). Thus, 16 prospective randomized clinical trials were selected for the final analysis. The schematic diagram of the study selection is illustrated in FIGURE 1. The characteristics of the included studies are summarized in TABLE 1.

A total of 1085 patients were included in the analysis of the endoscopic treatment efficacy in comparison with sham procedure, PPI or LARS. A total of 221 patients underwent TIF2, 145 surgical plications, 81 radiofrequency therapy; 42 endoscopic suturing, 32 injectable esophageal prostheses and 75 biocompatible non-resorbable copolymer. As for the control group a total of 294 patients underwent a sham procedure, 120 received PPIs,

TABLE 1. Descriptive table of RTC's characteristics.

\begin{tabular}{|c|c|c|c|c|c|c|}
\hline $\begin{array}{c}\text { Study/ Publication } \\
\text { Year }\end{array}$ & Population & $\begin{array}{l}\text { Intervention } \\
\text { Group }\end{array}$ & Control Group & $\begin{array}{l}\text { Outcome } \\
\text { (Efficacy) }\end{array}$ & $\begin{array}{l}\text { Follow up } \\
\text { (Months) }\end{array}$ & $\begin{array}{c}\text { Final } \\
\text { Analysis }\end{array}$ \\
\hline Håkansson, 2015(28) & Chronic GERD: 44 & TIF2: 22 & sham: 22 & Time in remission & 6 & ITT \\
\hline Hunter, $2015^{(29)}$ & Chronic GERD: 129 & TIF2/placebo: 87 & sham + PPI: 42 & ETSR & 6 & ITT \\
\hline Rinsma, $2015^{(30)}$ & Chronic GERD: 47 & TIF2: 32 & PPI: 15 & GERD HRQL score & 6 & ITT \\
\hline Witteman, 2015(31) & Chronic GERD: 60 & TIF2: 40 & PPI: 20 & $>50 \%$ GERD HRQL & 6 & $\mathrm{PP}$ \\
\hline Trad, 2015(32) & Chronic GERD: 63 & TIF2: 40 & PPI: 23 & ETSR & 6 & PP \\
\hline Corley, 2003 & Chronic GERD: 64 & Stretta: 35 & sham 29 & $>50 \%$ GERD HRQL & 6 & PP \\
\hline Arts, $2011^{(35)}$ & Chronic GERD: 22 & Stretta: 11 & sham: 11 & GERD HRQL score & 3 & ITT \\
\hline Antoniou, $2012^{(36)}$ & Chronic GERD: 60 & NDO surgical: 30 & LARS: 30 & GERD HRQL score & $3-12$ & $\mathrm{PP}$ \\
\hline Schwartz, $2007^{(37)}$ & Chronic GERD: 60 & Endocinch: 20 & $\begin{array}{c}\text { sham: } 20 \\
\text { Observation: } 20\end{array}$ & ETSR & 3 & ITT \\
\hline Coron, $2008^{(41)}$ & Chronic GERD: 43 & Stretta: 23 & PPI: 20 & Time in remission & $6-12$ & ITT \\
\hline Montgomery, $2006^{(42)}$ & Chronic GERD: 46 & Endocinch: 22 & sham: 24 & Time in remission & 3 & ITT \\
\hline Aziz, $2010^{(43)}$ & Chronic GERD: 36 & Stretta: 12 & $\begin{array}{c}\text { sham: } 12 \\
\text { Observation:12 }\end{array}$ & Time in remission & 12 & ITT \\
\hline
\end{tabular}

GERD: gastroesophageal reflux disease, HRQL: health related quality of life, PPI: proton pump inhibitors, LARS: laparoscopic antireflux surgery, TIF: transoral incisionless fundoplication, ITT: intention to treat, ETSR: elimination of troublesome regurgitation, PP: per protocol. 
and 63 underwent LARS. Studies consistently scored well on description of study aims, description of main findings, clarity in reporting of unplanned retrospective analyses, appropriate use of statistical tests, and use of accurate main outcome measures, and consistently scored poorly on blinding of subjects and assessors and patent allocation.

According to the risk of bias assessment of each individual study, we observed that a proper outcome description, a question to be investigated, randomization, patient losses and subject group prognosis were properly reported. Adequate allocation was done by $75 \%$ (12/16), double blinding was properly described by $40 \%(7 / 16)$ of trials and analysis by intention to treat was done by the $63 \%(10 / 16)$ of the studies. All studies had a JADAD scale over $>3$ with an overall average of 4.1. (FIGURE 2.A and FIGURE 2.B).

\section{Study outcomes \\ - Efficacy of endoscopic treatments versus sham and PPI}

A total of 707 patients, divided into 3, 6 and 12 follow up periods, from 10 trials were analyzed to evaluate the overall efficacy of the different endoscopic treatment devices versus any other intervention. Endoscopic treatments were performed in 395: Stretta ${ }^{\circledR}$, Enteryx $^{\circledR}$, TIF2, NDO surgical ${ }^{\circledR}$, Endocinch $^{\circledR}$, and 312 patients from the control group received: sham, PPI, sham + PPI together.

The overall risk-difference analysis (RD) showed a statistically significance difference $(P<0.00001)$ in evaluating the treatment ef- ficacy between the two groups (RD $-0.35,95 \%$ CI $-0.42,-0.28$ ), in favor of endoscopic treatment and demonstrating no heterogeneity between the trials $\left(\mathrm{I}^{2}: 0 \%\right)$. The Number needed to treat (NNT) was: 2.85 . Endoscopic treatments were effective in treating chronic GERD in $62 \%$ of the patients in comparison to the $25 \%$ of patients from the control group.

For the 3 months follow up subgroup analysis, a total of 263 patients from three trials were included. The RD showed a statistically significance difference $(P<0.00001)$ for the treatment efficacy between the two groups (RD $-0.38,95 \%$ CI $-0.49,-0.28$ ), in favor of endoscopic treatment and demonstrating no heterogeneity between the trials $\left(\mathrm{I}^{2}: 0 \%\right)$. The NNT was 2.63 . For the 6 months follow up subgroup analysis, a total of 377 patients from 6 trials were included. The RD analysis showed a statistically significance difference $(P<0.00001)$ for the treatment efficacy between the two groups (RD - $0.36,95 \%$ CI $-0.45,-0.26$ ) in favor of endoscopic treatments and demonstrating low heterogeneity between the trials ( $\mathrm{I}^{2}$ : $7 \%$ ). The NNT was 2.77 . For the 12 months follow up subgroup analysis, a total of 67 patients from two trials were included. The RD showed no statistically significance difference $(P<0.06)$ for the treatment efficacy between the two groups (RD - $0.20,95 \%$ CI -0.41 , -0.01 ) with no heterogeneity between trials ( $\left.I^{2}: 0 \%\right)$. (FIGURE 3 ).

\section{- Subgroup analysis}

We decided to make a subgroup analysis for the efficacy of the different endoscopic procedures to any type of intervention and to only sham procedure.

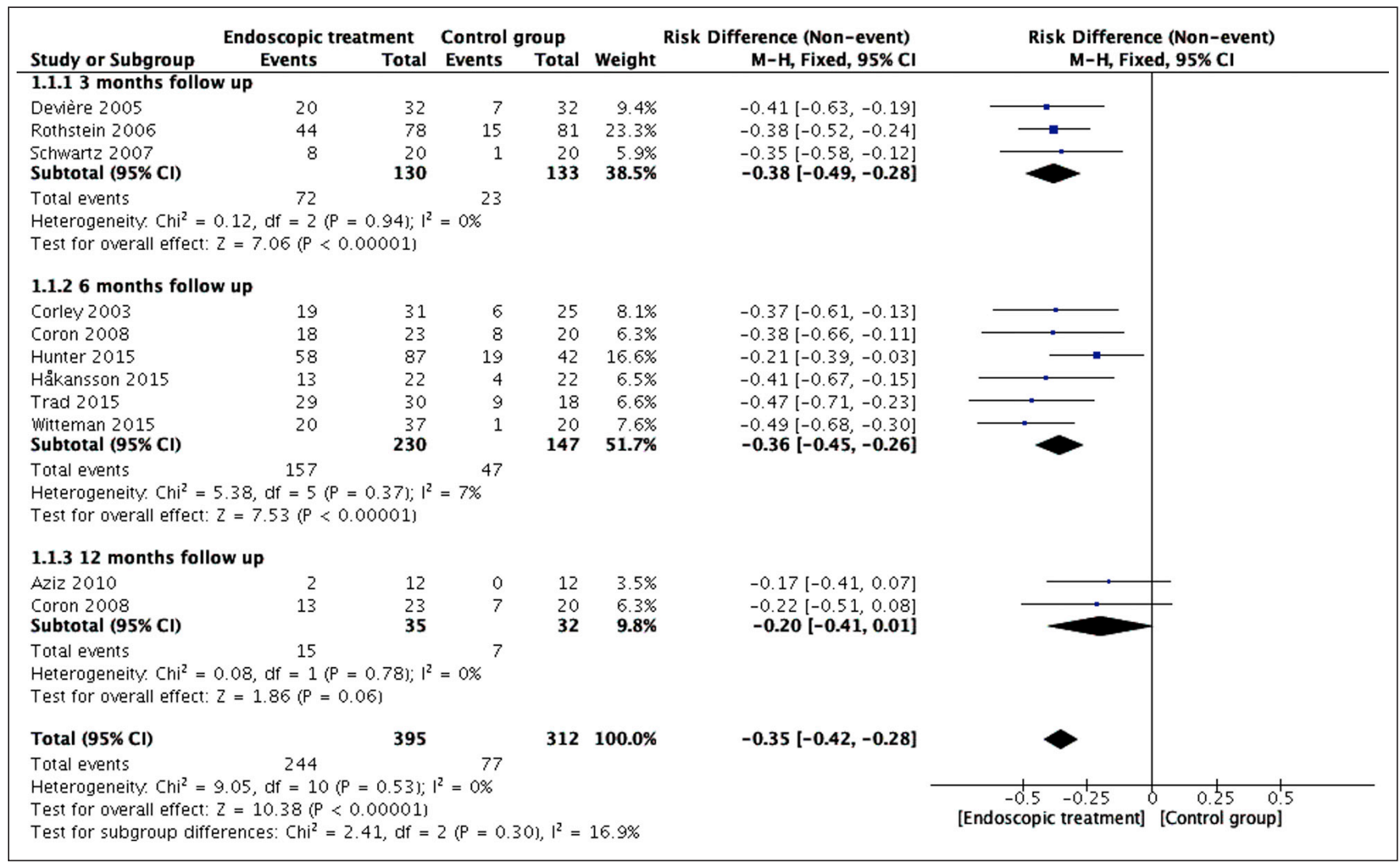

FIGURE 3. Efficacy of endoscopic treatments versus sham and PPI. 


\section{- Efficacy of endoscopic treatments versus}

\section{pharmacological (PPI) treatment}

A total of 320 patients from four trials were analyzed. Follow up was divided in 6 and 12 periods. Endoscopic interventions were performed in 200 patients: Stretta ${ }^{\circledR}$, TIF2, and 120 patients from the control group received: PPI and sham + PPI. The overall RD analysis showed a statistically significance difference $(P<0.00001)$ in treatment efficacy between the two groups (RD $-0.33,95 \%$ CI $-0.43,-0.22)$, favoring the endoscopic treatments and demonstrating a low heterogeneity between the trials $\left(\mathrm{I}^{2}: 39 \%\right)$. The NNT was 3.03. The different endoscopic treatments were effective in treating chronic GERD in $69 \%$ of the patients in compared to the $37 \%$ of patients treated with PPIs or sham + PPI.

For the 6 months follow up subgroup analysis, a total of 277 patients from four trials were included. The RD showed a statistically significance difference $(P<0.00001)$ for the treatment efficacy between the two groups (RD $-0.34,95 \%$ CI $-0.45,-0.24$ ) favoring endoscopic treatments and demonstrating a moderate heterogeneity between the trials $\left(\mathrm{I}^{2}: 45 \%\right)$. The NNT was 2.94 .

For the 12 months follow up subgroup analysis, a total of 43 patients from one trial were included. The RD showed no statistically significance difference $(P: 0.15)$ between the two groups (RD $-0.22,95 \%$ CI $-0.51,0.08)$. (FIGURE 4).

\section{- Efficacy of endoscopic treatments vs sham procedure}

A total of 387 patients, from 6 trials were included. Follow up was divided in 3, 6 and 12-month periods. Endoscopic interventions were performed in 195 patients: Stretta ${ }^{\circledR}$, Enteryx $^{\circledR}$, TIF2, NDO surgical ${ }^{\circledR}$, Endocinch $^{\circledR}$, and 192 patients underwent sham procedure for control.

The overall RD analysis showed a statistically significance difference $(P<0.00001)$ in treatment efficacy between the two groups
(RD - $0.37,95 \%$ CI $-0.46,-0.28$ ), favoring the endoscopic treatments and demonstrating no heterogeneity between trials $\left(\mathrm{I}^{2}: 0 \%\right)$. The NNT was 2.70. The different endoscopic treatments were effective in treating chronic GERD in 54\% of the patients in comparison to the $17 \%$ of patients treated with sham.

For the 3 months follow up subgroup analysis, a total of 263 patients from three trials were included. The RD showed a statistically significance difference $(P<0.00001)$ in evaluating the treatment efficacy between the two groups (RD - $0.38,95 \%$ CI $-0.49,-0.28$ ) favoring endoscopic treatments and demonstrating no heterogeneity between trials $\left(\mathrm{I}^{2}: 0\right)$. The NNT was: 2.63 .

For the 6 months follow up subgroup analysis, a total of 100 patients from two randomized trials were included. The RD showed a statistically significance difference $(P<0.00001)$ in evaluating the treatment efficacy between the 2 groups (RD $-0.39,95 \%$ CI $-0.57,-0.21)$ favoring endoscopic treatments and demonstrating no heterogeneity between the trials $\left(\mathrm{I}^{2}: 0 \%\right)$. The NNT was: 2.56 .

For the 12 months follow up subgroup analysis. Total of 24 patients from 1 randomized trial were included. The RD showed no statistically significance difference $(P<0.17)$ between the two groups (RD -0.17, 95\% CI -0.41, 0.07). (FIGURE 5).

\section{- Summary of objective outcomes analyzed}

Endoscopic therapies had consistent results showing a statistically significant $(P<0.0001)(\mathrm{RD}-0.42,95 \% \mathrm{CI}-0.62,-0.21)\left(\mathrm{I}^{2}\right.$ : $0 \%$ ) improvement in healing of esophagitis with no heterogeneity between trials in up to 12 months of follow up. The outcomes of normalization of esophageal acid $\mathrm{pH}(P<0.03)(\mathrm{RD}-0.13,95 \% \mathrm{CI}$ $-0.26,-0.01)\left(\mathrm{I}^{2}: 76 \%\right)$, LESRP $(P<0.00001)(\mathrm{MD}-1.15,95 \% \mathrm{CI}$ $-1.47,-0.83)\left(\mathrm{I}^{2}: 94 \%\right)$, mean percent of total time of esophageal $\mathrm{pH}<4(P<0.00001)(\mathrm{MD}-1.19,95 \% \mathrm{CI}-1.53,-0.84)\left(\mathrm{I}^{2}: 78 \%\right)$ and mean number of reflux episodes $(P<0.00001)(\mathrm{MD}-12.80,95 \% \mathrm{CI}$

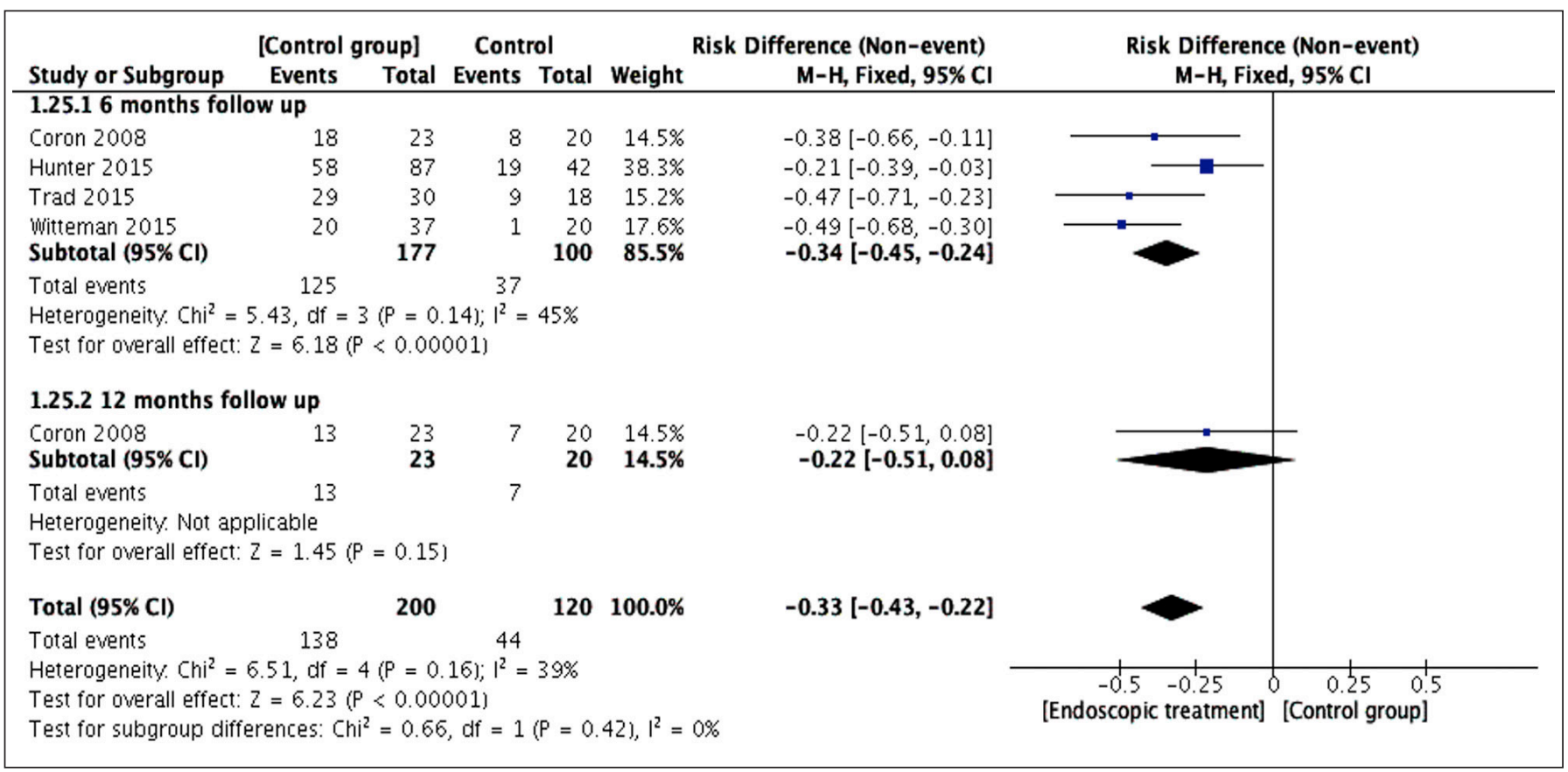

FIGURE 4. Efficacy of endoscopic treatments versus pharmacological (PPI) treatment. 


\begin{tabular}{|c|c|c|c|c|c|c|c|c|}
\hline Study or Subgroup & \multicolumn{2}{|c|}{ Endoscopic treatment } & \multicolumn{2}{|c|}{ Sham procedure } & \multicolumn{2}{|c|}{ Risk Difference (Non-event) } & \multicolumn{2}{|c|}{$\begin{array}{l}\text { Risk Difference (Non-event) } \\
\text { M-H, Fixed, } 95 \% \mathrm{Cl}\end{array}$} \\
\hline \multicolumn{7}{|c|}{ 1.26.1 3 months follow up } & & \\
\hline Devière 2005 & 20 & 32 & 7 & 32 & $16.6 \%$ & $-0.41[-0.63,-0.19]$ & $\bar{L}$ & \\
\hline Rothstein 2006 & 44 & 78 & 15 & 81 & $41.1 \%$ & $-0.38[-0.52,-0.24]$ & & \\
\hline $\begin{array}{l}\text { Schwartz } 2007 \\
\text { Subtotal }(\mathbf{9 5 \%} \mathrm{Cl})\end{array}$ & 8 & $\begin{array}{r}20 \\
130\end{array}$ & 1 & $\begin{array}{r}20 \\
133\end{array}$ & $\begin{array}{l}10.4 \% \\
68.1 \%\end{array}$ & $\begin{array}{l}-0.35[-0.58,-0.12] \\
-\mathbf{0 . 3 8}[\mathbf{- 0 . 4 9 , - 0 . 2 8}]\end{array}$ & & \\
\hline \multicolumn{7}{|c|}{$\begin{array}{l}\text { Heterogeneity. } \mathrm{Chi}^{2}=0.12, \mathrm{df}=2(\mathrm{P}=0.94) ; \mathrm{I}^{2}=0 \% \\
\text { Test for overall effect: } Z=7.06(\mathrm{P}<0.00001)\end{array}$} & & \\
\hline \multicolumn{7}{|c|}{1.26 .26 months follow up } & & \\
\hline $\begin{array}{l}\text { Corley } 2003 \\
\text { Håkansson } 2015 \\
\text { Subtotal }(\mathbf{9 5 \%} \mathbf{C l})\end{array}$ & $\begin{array}{l}19 \\
13\end{array}$ & $\begin{array}{l}31 \\
22 \\
\mathbf{5 3}\end{array}$ & $\begin{array}{l}6 \\
4\end{array}$ & $\begin{array}{l}25 \\
22 \\
47\end{array}$ & $\begin{array}{l}14.3 \% \\
11.4 \% \\
25.7 \%\end{array}$ & $\begin{array}{l}-0.37[-0.61,-0.13] \\
-0.41[-0.67,-0.15] \\
-0.39[-0.57,-0.21]\end{array}$ & & \\
\hline \multicolumn{7}{|c|}{$\begin{array}{l}\text { Heterogeneity. } \mathrm{Chi}^{2}=0.04, \mathrm{df}=1(\mathrm{P}=0.84) ; \mathrm{I}^{2}=0 \% \\
\text { Test for overall effect: } Z=4.32(\mathrm{P}<0.0001)\end{array}$} & & \\
\hline \multicolumn{7}{|c|}{ 1.26.3 12 months follow up } & & \\
\hline $\begin{array}{l}\text { Aziz } 2010 \\
\text { Subtotal }(95 \% \mathrm{CI})\end{array}$ & 2 & $\begin{array}{l}12 \\
12\end{array}$ & 0 & $\begin{array}{l}12 \\
12\end{array}$ & $\begin{array}{l}6.2 \% \\
6.2 \%\end{array}$ & $\begin{array}{l}-0.17[-0.41,0.07] \\
\mathbf{- 0 . 1 7}[-\mathbf{0 . 4 1 , 0 . 0 7}]\end{array}$ & & \\
\hline \multicolumn{7}{|c|}{$\begin{array}{l}\text { Heterogeneity. Not applicable } \\
\text { Test for overall effect: } Z=1.37(P=0.17)\end{array}$} & & \\
\hline Total $(95 \% \mathrm{Cl})$ & & 195 & & 192 & $100.0 \%$ & $-0.37[-0.46,-0.28]$ & & \\
\hline Total events & 106 & & 33 & & & & & \\
\hline \multicolumn{7}{|c|}{$\begin{array}{l}\text { Heterogeneity. } \mathrm{Chi}^{2}=3.03, \mathrm{df}=5(\mathrm{P}=0.70) ; \mathrm{I}^{2}=0 \% \\
\text { Test for overall effect: } Z=8.36(\mathrm{P}<0.00001) \\
\text { Test for subgroup differences: } \mathrm{Chi}^{2}=2.77, \mathrm{df}=2(\mathrm{P}=0.25), \mathrm{I}^{2}=27.9 \%\end{array}$} & $\begin{array}{cc}-0.5 & -0.25 \\
\text { [Endoscopic treatment] }\end{array}$ & ] 0.25 \\
\hline
\end{tabular}

FIGURE 5. Efficacy of endoscopic treatment vs sham procedure.

$-15.04,-10.56)\left(\mathrm{I}^{2}: 98 \%\right)$ were statistically significant in favor to the endoscopic procedures but with a high heterogeneity between trials in up to 12 months of follow up, with the exemption of the mean number of reflux episodes which was statistically significant up to 3 months follow up. When comparing endoscopic therapies only to sham, the results are similar, except for healing of esophagitis since there is no available data to show this comparison.

\section{- Summary of subjective outcomes analyzed}

When endoscopic treatments were compared to any other intervention (PPIs or LARS) or sham, the time in remission $(P<0.00001)$ (RD $-0.29,95 \% \mathrm{CI}-0.38,-0.20)\left(\mathrm{I}^{2}: 0 \%\right)$, number of patients with GERD HRLQ score $>50 \%$ improvement $(P<0.00001)$ (RD -0.38 , $95 \% \mathrm{CI}-0.47,-0.30)\left(\mathrm{I}^{2}: 11 \%\right)$, elimination of troublesome regurgitation $(P<0.00001)(\mathrm{RD}-0.32,95 \% \mathrm{CI}-0.43,-0.20)\left(\mathrm{I}^{2}: 10 \%\right)$, were statistically significant in favor to the endoscopic procedures with very low heterogeneity between the trials up to 6 and 12 months follow up. Interestingly, the mean GERD HRQL score $(P<0.00001)$ (MD $-0.92,95 \%$ CI $-1.24,-0.60)\left(\mathrm{I}^{2}: 98 \%\right)$, the heartburn score $(P<0.00001)(\mathrm{MD}-0.53,95 \%$ CI $-0.60,-0.46)\left(\mathrm{I}^{2}: 80 \%\right)$ and DeMeester score $(P<0.00001)(\mathrm{MD}-5.14,95 \%$ CI $-6.43,-3.48)\left(\mathrm{I}^{2}\right.$ : $96 \%$ ), showed statistically significance in favor to endoscopy up to 6 and 12 months but with a high heterogeneity, and the SF-36 score $(P<0.00001)(\mathrm{MD} 4.75,95 \%$ CI $3.76,5.74)\left(\mathrm{I}^{2}: 77 \%\right)$, showed improvement in favor to other therapies compared to endoscopy up to 12 months follow up, but with high heterogeneity between studies. When comparing endoscopic therapies only to sham, the results were similar.

\section{DISCUSSION}

A wide-range of GERD patients with poorly controlled symptoms following daily PPIs dependence is actively looking for an effective anti-reflux procedure. Long term PPIs usage is expensive and has several well-known side effects. Laparoscopic Nissen fundoplication is the surgical "gold standard", however, minimally invasive endoscopic treatments may offer the advantages of being safer with faster recovery times.

As stated above, endoscopic treatments for GERD can be categorized into three groups: 1 . Endoluminal suture or plication of the gastroesophageal junction; 2. Radiofrequency (RF) thermal therapy of the lower esophageal sphincter (LES); and 3. Injection/implantation of biopolymers in GEJ. This meta-analysis compares the efficacy of different endoscopic procedures to any other intervention (sham procedure, PPIs or LARS). The efficacy of these treatments was measured by different objective and subjective outcomes.

As for the main outcome, which evaluates the general efficacy of the different endoscopic procedures versus sham and PPIs, we observed an overall statistically significant difference favoring the endoscopic procedures with no heterogeneity between the randomized clinical trials. Endoscopic treatment was more effective in treating chronic GERD in $62 \%$ of the patients, in comparison to 25 $\%$ of patients treated by any of these interventions. In the individual subgroup analysis, we observed a statistically significant difference in favor of the endoscopic procedures in the 3 and 6 months follow up groups, but this difference was not present in studies that 
had 12 months of follow up. To date, there are no randomized studies evaluating the efficacy of endoscopic procedures with over 12 months of follow up. In addition, there is treatment crossover since a group of patients who received endoscopic interventions required additional therapies, which limits the follow up analysis.

There are other prospective cohort studies, which reported a prolonged follow up period with good results. For example, for the TIF2 device, Testoni et al. ${ }^{(21)}$ prospectively followed 50 patients, 32 patients completed 3 years and 14 patients completed 6 years of follow-up. Another two prospective studies evaluated the long-term efficacy of the Stretta device, the Dughera et al. study ${ }^{(22)}$ included 86 patients, where 26 patients completed 8 years of follow-up and the Noar et al. ${ }^{(23)}$ evaluated 217 patients and reported a 10 -year follow-up. Interestingly, many objective measurements return to baseline but a significant proportion of patients show continued improvement in subjective outcomes and remain off PPIs.

For the Muse system two different trials have been reported, one for 6 months and other for 4 years follow-up, both showing promising objective and subjective outcomes improvement $t^{(24,25)}$. This device was not included in our study because no randomized clinical trials are available to date.

In this meta-analysis, we included RCTs that described the effectiveness of the NDO surgical ${ }^{\circledR}$, Endocinch ${ }^{\circledR}$, Enteryx ${ }^{\circledR}$ and Gatekeeper ${ }^{\circledR}$ devices as individually, they show improvement in outcomes. It is important to note that these devices are now off the market in the USA due to safety concerns ${ }^{(26)}$.

Subgroup analysis was performed comparing the efficacy of the different endoscopic procedures versus PPIs and sham procedure separately. For the first subgroup, comparing the efficacy of endoscopic treatments to PPIs, we were able to perform a meta-analysis from four randomized clinical trials and we observed a statistically significant difference favoring the endoscopic treatments with no significant heterogeneity between trials. Endoscopic treatments were more effective in treating chronic GERD in $69 \%$ of the patients, in compared to the $37 \%$ of patients treated by PPI intervention. In the individual subgroup analysis, we observed a statistically significant difference in favor of the endoscopic procedures in the 6 months follow up group, but this difference was not present in studies that had 12 months of follow up. This difference was lost, probably due to insufficient data since there was only one study evaluating outcomes at this time period ${ }^{(41)}$.

In the analysis of the second subgroup, comparing the efficacy of endoscopic treatments to sham, we observed a statistically significant difference favoring endoscopic treatments with no heterogeneity between trials. Endoscopic treatments were more effective in treating GERD in $54 \%$ of the patients compared to the $12 \%$ of patients that underwent a sham procedure. As in the previous subgroup, we observed a statistically significant difference in favor of the endoscopic procedures in the 3 and 6 months follow up groups, but this difference was not present in studies that had 12 months of follow up. likely due to insufficient data since there was only one study evaluating outcomes at this time period ${ }^{(43)}$.

As for limitations of this meta-analysis, there is a high degree of heterogeneity when analyzing different outcomes since the reporting of multiple subjective and objective outcomes is not uniform. In addition, very few studies provide reliable information beyond 6 months. Many patients were offered alternative interventions at this time period and the actual benefit of the endoscopic intervention is compromised. Importantly, there was insufficient data to perform a subgroup analysis for LARS separately.
There are several studies comparing laparoscopic surgery to PPIs. A randomized study described by Galmiche et al..$^{(8)}$ comparing LARS vs PPI with a 5-year follow up, showed that both groups presented higher rates of "time in remission" (for LARS, defined as need for acid suppressive therapy and for PPIs, as inadequate symptom control after dose adjustment). A similar, large randomized trial by Hatlebakk et al. ${ }^{(27)}$ comparing LARS vs PPIs at 6-months and 5-years follow up, showed that both therapies were effective in controlling esophageal acid exposure. In our study, the time in remission and esophageal acid exposure rates were statistically significant in up to 6 months with no heterogeneity and 12 months with high heterogeneity, respectively, in favor of endoscopic treatments.

In this review, most of the studies report clinically significant moderate to severe postprocedure related adverse events such as epigastric pain, musculoskeletal pain, dysphagia, sore throat, chest pain, nausea and vomit, bloating and flatulence among others, that were treated clinically, with complete resolution and no major sequelae. Reporting a total of 312 events of 1073 procedures. The event rate of $38 \%$ for the endoscopic treatments, $24 \%$ for the sham procedure, $4 \%$ for the PPI group and $2 \%$ for the LARS group.

However, there are studies that have reported more serious procedure related adverse events. A trial that evaluated the Gatekeeper $^{\circledR}$ device ${ }^{(38)}$ showed two procedure related esophageal wall perforations, one managed surgically and other clinically with no long-term sequelae. A trial evaluating the NDO device, described a procedure related pneumomediastinum and pneumoperitoneum ${ }^{(40)}$, managed clinically and without any further intervention. A trial assessing the NDO vs LARS ${ }^{(33)}$, reported one post- procedure gastric bleeding related to the NDO device, managed clinically without sequelae. From all trials, one death at 11 months after the intervention (TIF2) was reported ${ }^{(31)}$, this mortality case was considered probably unrelated to the intervention.

This meta-analysis provides outcomes of all the endoscopic procedures available to date to treat patients with chronic GERD. Since this patient population is similar across these studies and physiologically, all endoscopic therapies attempt to increase the pressure of the LES by different mechanisms, pooling the results of these RCTs in a systematic fashion, provides a detailed analysis of objective and subjective outcomes that may aid in bridging the gap between medical therapy and conventional surgery in patients who suffer from chronic GERD.

\section{CONCLUSION}

The development of alternative treatment options for chronic GERD is of interest. Patients are destined to lifelong PPIs or antireflux surgery, although current conventional surgical approaches have been well studied and are relatively safe, recent advances in minimally invasive endoluminal techniques have introduced the possibility of incisionless procedures.

This systematic review and meta-analysis shows a good shortterm efficacy in favor of endoscopic procedures when comparing them to a sham and pharmacological or surgical treatment. Current data on endoluminal therapies for the management of GERD are promising; however, the role of endoscopy within the GERD treatment algorithm remains unclear. More studies, especially in endoscopic plication devices, are necessary because the current available data are limited by conflicting results, lack of long-term efficacy and non-homogeneous outcome reporting. In conclusion, larger prospective, multicenter, randomized studies are necessary, 
to identify the role of endoscopic therapies before they can be advocated as an effective GERD solution.

\section{ACKNOWLEDGEMENTS}

We will like to thank all the authors and colleagues who contributed to this meta-analysis. To Dr. Cesar de Clemente Junior, Dr. Emmanuel Coronel and Dr. Paulo Sakai for contributing in writing the manuscript.

\section{Authors' contributions}

Study concept and design by Coronel MA, Bernardo WM and Moura EGH; acquisition of data, analysis and interpretation of data, statistical analysis by Coronel MA, Bernardo WM, Moura DTH, Moura ETH, Ribeiro IB; drafting of the manuscript and critical revision of the manuscript for important intellectual content by Coronel MA, Bernardo WM, Moura EGH; Study supervision: Bernardo WM, Moura DTH and Moura EGH.

Coronel MA, Bernardo WM, Moura DTH, Moura ETH, Ribeiro IB, Moura EGH. A eficácia dos diferentes tratamentos endoscópicos versus métodos sham, farmacológicos ou cirúrgicos para o refluxo gastroesofágico crônico: uma revisão sistemática e meta-análise. Arq Gastroenterol. 2018,55(3):296-305.

RESUMO - Contexto - Os tratamentos endoscópicos para a doença do refluxo gastroesofágico (DRGE) ainda estão em evolução e a maioria dos estudos publicados abordam o alívio dos sintomas em curto prazo. Objetivo - Pretendemos realizar uma revisão sistemática e meta-análise focada na avaliação da eficácia dos diferentes procedimentos endoscópicos. Métodos - A pesquisa foi restrita a ensaios clínicos randomizados em MedLine, Cochrane, SciELO e EMBASE para pacientes com DRGE crônica ( $>6$ meses), com mais de 18 anos e acompanhamento disponível por pelo menos 3 meses. O principal desfecho foi avaliar a eficácia dos diferentes tratamentos endoscópicos em comparação com o tratamento sham, farmacológico ou cirúrgico. A eficácia foi medida por diferentes resultados subjetivos e objetivos. Resultados - Analisamos dados de 16 ensaios clínicos randomizados, totalizando 1085 pacientes. A eficácia dos tratamentos endoscópicos em comparação com o tratamento com sham e inibidores da bomba de prótons mostrou uma diferença significativa até 6 meses a favor da endoscopia sem heterogeneidade $(P<0,00001)\left(\mathrm{I}^{2}: 0 \%\right)$. A análise do subgrupo mostrou diferença estatisticamente significativa até 6 meses a favor da endoscopia: endoscopia vs inibidores da bomba de prótons $(P<0,00001)\left(\mathrm{I}^{2}: 39 \%\right)$. Endoscopia vs sham $(P<0,00001)\left(I^{2}: 0 \%\right)$. A maioria dos resultados subjetivos e objetivos foram estatisticamente significativos em favor da endoscopia até 6 e 12 meses de acompanhamento. Conclusão - Esta revisão sistemática e meta-análise mostrou uma boa eficácia a curto prazo em favor dos procedimentos endoscópicos ao compará-los a tratamento sham, farmacológico ou cirúrgico. Não existem dados sobre o acompanhamento a longo prazo e isso deve ser explorado em estudos futuros.

DESCRITORES - Refluxo gastroesofágico, terapia. Endoscopia gastrointestinal. Seguimentos. Revisão.

\section{REFERENCES}

1. Camilleri M, Dubois D, Coulie B, Jones M, Kahrilas PJ, Rentz AM, et al Prevalence and socioeconomic impact of upper gastrointestinal disorders in the United States: Results of the US upper gastrointestinal study. Clin Gastroenterol Hepatol. 2005;3:543-52.

2. Moraes-Filho JPP, Chinzon D, Eisig JN, Hashimoto CL, Zaterka S. Prevalence of heartburn and gastroesophageal reflux disease in the urban Brazilian population. Arq Gastroenterol. 2005;42:122-7.

3. El-Serag HB, Sweet S, Winchester CC, Dent J. Update on the epidemiology of gastro-oesophageal reflux disease: a systematic review. Gut. 2014;63:871-80.

4. Moraes-Filho JPP. Gastroesophageal reflux disease: prevalence and management in Brazil. Best Pract Res Clin Gastroenterol. 2004;18:23-6.

5. Edgren G, Adami HO, Vainio EW, Nyrén O. A global assessment of the oesophageal adenocarcinoma epidemic. Gut. 2013;62:1406-14.

6. Boeckxstaens G, El-Serag HB, Smout AJPM, Kahrilas PJ. Symptomatic reflux disease: the present, the past and the future. Gut. 2014;63:1185-93.

7. Demeester TR, Johnson LF, Kent AH. Evaluation of current operations for the prevention of gastroesophageal reflux. Ann Surg. 1974;180:511-25.

8. Galmiche J-P, Hatlebakk J, Attwood S, Ell C, Fiocca R, Eklund S, et al. Laparoscopic antireflux surgery vs esomeprazole treatment for chronic GERD: the LOTUS randomized clinical trial. JAMA. 2011;305:1969-77.

9. Spechler SJ, Lee E, Ahnen D, Goyal RK, Hirano I, Ramirez F, et al. Long-term outcome of medical and surgical therapies for gastroesophageal reflux disease: follow-up of a randomized controlled trial. JAMA. 2001;285:2331-8.

10. Rothstein RI. Endoscopic therapy of gastroesophageal reflux disease: Outcomes of the randomized-controlled trials done to date. J Clin Gastroenterol. 2008;42:594-602.

11. Huang X, Chen S, Zhao H, Zeng X, Lian J, Tseng Y, Chen J. Efficacy of transoral incisionless fundoplication (TIF) for the treatment of GERD : a systematic review with meta-analysis. Surg Endosc. 2017;31:1032-44.

12. Lipka S, Kumar A, Richter JE. No evidence for efficacy of radiofrequency ablation for treatment of gastroesophageal reflux disease: a systematic review and meta-analysis. Clin Gastroenterol Hepatol. 2015;13:1058-67.e1

13. Moher D, Liberati A, Tetzlaff J, Altman DG; PRISMA Group. Preferred reporting items for systematic reviews and meta-analyses: the PRISMA statement. BMJ. 2009;339:b2535.
14. Jadad, A. Moore RA, Carroll D, Jenkinson C, Reynolds DJ, Gavaghan DJ, McQuay HJ. Assessing the quality of reports of randomized clinical trials: is blinding necessary? Control Clin Trials. 1996;17:1-12.

15. Vakil N, van Zanten S V, Kahrilas P, Dent J, Jones R, Global Consensus Group. The Montreal definition and classification of gastroesophageal reflux disease: a global evidence-based consensus. Am J Gastroenterol. 2006;101:1900-20; quiz 1943.

16. Velanovich V, Vallance S, Gusz J, Tapia F, Harkabus M. Quality of life scale for gastroesophageal reflux disease. J Am Call Sur. 1996;183:217-24.

17. Chan Y, Ching JYL, Cheung CMY, Tsoi KK, Polder-Verkiel S, Pang SH, et al. Development and validation of a disease-specific quality of life questionnaire for gastro-oesophageal reflux disease: the GERD-QOL questionnaire. Aliment Pharmacol Ther. 2010;31:452-60.

18. Jamieson JR, Stein HJ, DeMeester TR, Bonavina L, Schwizer W, Hinder RA, et al. Ambulatory 24-h esophageal $\mathrm{pH}$ monitoring: normal values, optimal thresholds, specificity, sensitivity, and reproducibility. Am J Gastroenterol. 1992;87: 1102-11.

19. DerSimonian R, Laird N. Meta-analysis in clinical trials. Control Clin Trials. 1986;7:177-88.

20. Easterbrook PJ, Berlin JA, Gopalan R, Matthews DR. Publication bias in clinical research. Lancet. 1991;337:867-72.

21. Testoni PA, Testoni S, Mazzoleni G, Vailati C, Passaretti S. Long-term efficacy of transoral incisionless fundoplication with Esophyx (Tif 2.0) and factors affecting outcomes in GERD patients followed for up to 6 years: a prospective single-center study. Surg Endosc Other Interv Tech. 2015;29:2770-80.

22. Dughera L, Rotondano G, De Cento M, Cassolino P, Cisarò F. Durability of stretta radiofrequency treatment for GERD: Results of an 8-year follow-up. Gastroenterol Res Pract. 2014;2014:531907.

23. Noar M, Squires P, Noar E, Lee M. Long-term maintenance effect of radiofrequency energy delivery for refractory GERD: a decade later. Surg Endosc Other Interv Tech. 2014;28:2323-33.

24. Zacherl J, Roy-Shapira A, Bonavina L, Bapaye A, Kiesslich R, Schoppmann SF, et al. Endoscopic anterior fundoplication with the Medigus Ultrasonic Surgical Endostapler (MUSETM) for gastroesophageal reflux disease: 6-month results from a multi-center prospective trial. Surg Endosc. 2015;29:220-9. 
25. Kim HJ, Kwon C-I, Kessler WR, Selzer DJ, McNulty G, Bapaye A, et al. Longterm follow-up results of endoscopic treatment of gastroesophageal reflux disease with the MUSETM endoscopic stapling device. Surg Endosc. 2016;30: 3402-8.

26. ASGE Technology Committee, Thosani N, Goodman A, Manfredi M, Navaneethan U, Parsi MA, et al. Endoscopic anti-reflux devices. Gastrointest Endosc. 2017;86:931-48.

27. Hatlebakk JG, Zerbib F, Bruley des Varannes S, Attwood SE, Ell C, Fiocca R, et al. Gastroesophageal acid reflux control 5 years after antireflux surgery, compared with long-term esomeprazole therapy. Clin Gastroenterol Hepatol. 2016;14:678-685.e3.

28. Håkansson B, Montgomery M, Cadiere GB, Rajan A, Bruley des Varannes S, Lerhun M, et al. Randomized clinical trial: Transoral incisionless fundoplication vs. sham intervention to control chronic GERD. Aliment Pharmacol Ther. 2015;42:1261-70.

29. Hunter JG, Kahrilas PJ, Bell RCW, Wilson EB, Trad KS, Dolan JP, et al. Efficacy of transoral fundoplication vs omeprazole for treatment of regurgitation in a randomized controlled trial. Gastroenterology. 2015;148:324-33.

30. Rinsma NF, Farré R, Bouvy ND, Masclee AAM, Conchillo JM. The effect of endoscopic fundoplication and proton pump inhibitors on baseline impedance and heartburn severity in GERD patients. Neurogastroenterol Motil. 2015;27: 220-8.

31. Witteman BPL, Conchillo JM, Rinsma NF, Betzel B, Peeters A, Koek GH, et al. Randomized controlled trial of transoral incisionless fundoplication vs proton pump inhibitors for treatment of gastroesophageal reflux disease. Am J Gastroenterol. 2015;110:531-42.

32. Trad KS, Barnes WE, Simoni G, Shughoury AB, Mavrelis PG, Raza M, et al. Transoral incisionless fundoplication effective in eliminating GERD symptoms in partial responders to proton pump inhibitor therapy at 6 months. Surg Innov. 2015;22:26-40.

33. Kaindlstorfer A, Koch OO, Antoniou SA, Asche K-U, Granderath FA, Pointner R. A randomized trial on endoscopic full-thickness gastroplication versus laparoscopic antireflux surgery in GERD patients without hiatal hernias. Surg Laparosc Endosc Percutan Tech. 2013;23:212-22.
34. Corley DA, Katz P, Wo JM, Stefan A, Patti M, Rothstein R, et al. Improvement of gastroesophageal reflux symptoms after radiofrequency energy: a randomized, sham-controlled trial. Gastroenterology. 2003;125:668-76.

35. Arts J, Bisschops R, Blondeau K, Farré R, Vos R, Holvoet L, et al. A double-blind sham-controlled study of the effect of radiofrequency energy on symptoms and distensibility of the gastro-esophageal junction in GERD. Am J Gastroenterol. 2012;107:222-30.

36. Antoniou SA, Koch OO, Kaindlstorfer A, Asche KU, Berger J, Granderath FA, et al. Endoscopic full-thickness plication versus laparoscopic fundoplication: a prospective study on quality of life and symptom control. Surg Endosc. 2012;26:1063-8.

37. Schwartz MP, Wellink H, Gooszen HG, Conchillo JM, Samsom M, Smout. Endoscopic gastroplication for the treatment of gastro-oesophageal reflux disease: a randomised, sham-controlled trial. Gut. 2007;56:20-8.

38. Focken P, Cohen L, Edmundowicz SA, Binmoeller K, Rothstein RI, Smith D, et al. Prospective randomized controlled trial of an injectable esophageal prosthesis versus a sham procedure for endoscopic treatment of gastroesophageal reflux disease. Surg Endosc Other Interv Tech. 2010;24:1387-97.

39. Devière J, Costamagna G, Neuhaus H, Voderholzer W, Louis H, Tringali A, et al. Nonresorbable copolymer implantation for gastroesophageal reflux disease: A randomized sham-controlled multicenter trial. Gastroenterology. 2005;128:532-40.

40. Rothstein R, Filipi C, Caca K, Pruitt R, Mergener K, Torquati A, et al. Endoscopic full-thickness plication for the treatment of gastroesophageal reflux disease: a randomized, sham-controlled trial. Gastroenterology. 2006;131:704-12.

41. Coron E, Sebille V, Cadiot G, Zerbib F, Ducrotte P, Ducrot F, et al. Clinical trial: Radiofrequency energy delivery in proton pump inhibitor-dependent gastro-oesophageal reflux disease patients. Aliment Pharmacol Ther. 2008;28:1147-58.

42. Montgomery M, Håkanson B, Ljungqvist $\mathrm{O}$, Ahlman B, Thorell A. Twelve months' follow-up after treatment with the EndoCinch endoscopic technique for gastro-oesophageal reflux disease: A randomized, placebo-controlled study. Scand J Gastroenterol. 2006;41:1382-9.

43. Abdel Aziz AM, El-Khayat HR, Sadek A, Mattar SG, McNulty G, Kongkam P, et al. A prospective randomized trial of sham, single-dose Stretta, and double-dose Stretta for the treatment of gastroesophageal reflux disease. Surg Endosc Other Interv Tech. 2010;24:818-25. 